\title{
The Prognostic Factors in Patients With Sepsis After Operation of Gastrointestinal Tumors
}

Ren-Xiong Chen

Beijing Cancer Hospital https://orcid.org/0000-0003-0471-3449

\section{Zhou-Qiao Wu}

Beijing Cancer Hospital

Zi-Yu Li

Beijing Cancer Hospital

Hong-Zhi Wang ( $\square$ wanghz58@sina.com )

University Cancer Hospital \& Institute, Beijing https://orcid.org/0000-0003-0985-2157

Jia-Fu Ji

Beijing Cancer Hospital

Research article

Keywords: Prognostic factors, Sepsis, Gastrointestinal tumor

Posted Date: July 27th, 2020

DOI: https://doi.org/10.21203/rs.3.rs-47640/v1

License: (c) (i) This work is licensed under a Creative Commons Attribution 4.0 International License.

Read Full License 


\section{Abstract}

\section{Background}

We studied the clinical profiles and the prognostic factors in patients with sepsis after thegastrointestinal tumor surgery in ICU.

\section{Methods}

We retrospectively screened patients who underwent the gastrointestinal tumor surgery at the Peking University Cancer Hospital from January 2015 to December 2019. Among them, 181 patients who were diagnosed with sepsis in ICU were enrolled in our study. Cox regression was performed for multivariate adjusted factor analyses.

\section{Results}

The 90 -day all-cause mortality rate was $11.1 \%$ in our study. The univariate analysis showed that BMI, shock within $48 \mathrm{~h}$ after entering ICU, number of blood leukocytes, the ratio of lymphocytes to neutrophils, INR, creatinine, procalcitonin, lactic acid, oxygenation index, SOFA score within $24 \mathrm{~h}$ after entering ICU, APACHE II score within $24 \mathrm{~h}$ after entering ICU were statistically significant. In multiple analysis, we found that BMI $\triangle 20 \mathrm{~kg} / \mathrm{m}^{2}$ was a protective factor, while lactic acid $\triangle 3 \mathrm{mmol} / \mathrm{L}$ after entering the ICU and APACHE II score 20 within $24 \mathrm{~h}$ after entering ICU were independent risk factors on the prognosis of sepsis after the gastrointestinal tumor surgery in ICU.

Conclusion

The 90 -day all-cause mortality rate was $11.1 \%$ in our study. BMI $>20 \mathrm{~kg} / \mathrm{m}^{2}$ was a protective factor, while lactic acid $>3 \mathrm{mmol} / \mathrm{L}$ after entering the ICU and APACHE II score $>20$ within $24 \mathrm{~h}$ after entering ICU were independent risk factors on the prognosis of sepsis after the gastrointestinal tumor surgery in ICU.

\section{Background}

Sepsis is a worldwide problem. It is estimated that there are 31.5 million patients with sepsis every year in the world, which causes about 5.3 million deaths every year ${ }^{[1]}$. Sepsis is associated with high mortality and it can be caused by any types of infection. Pathogenic microorganisms include bacteria, fungi, viruses and parasites. As the previous definition of sepsis (infection plus SIRS) is too sensitive, the new definition of sepsis is the life-threatening organ dysfunction caused by the host's maladjusted response to infection. Organ dysfunction manifests that sepsis-related organ failure score was no less than two points ${ }^{[2]}$.

The most common postoperative infection of gastrointestinal tumor is abdominal infection. Early identification of infection, control of infection source, proper use of antibiotics and rapid resuscitation of critical patients are the cornerstone of abdominal infection management ${ }^{[3-6]}$. There are numerous factors 
affecting the prognosis of sepsis. It has been reported that the prognosis of sepsis is related to lactic acid, interleukin-6, PCT, CRP, HFABP and so on ${ }^{[7-11]}$. However, as the definition describes, sepsis is a syndrome with extreme heterogeneity. In the past, there were many reports on mortality of sepsis; however, few studies on the prognosis of patients with sepsis after gastrointestinal operation. The purpose of this study is to investigate the prognostic factors of patients with sepsis who were admitted to ICU after gastrointestinal operation.

\section{Methods}

Patients

From January 2015 to December 2019, a total of 1636 patients were admitted to ICU after surgery from Gastrointestinal Cancer Center of Peking University Cancer Hospital. According to the new definition of sepsis, 181 patients diagnosed with sepsis were enrolled in this study. Exclusion criteria: Patients were admitted to ICU for other reasons or did not have sepsis during ICU stay, or patients' sepsis occurred out of ICU stay.

Therapeutic method

For sepsis patients, we have active anti-infection treatment, sent etiology examination and tried to find the source of infection. For patients with septic shock, we took the following measures: First, bestowed broadspectrum antibiotics within one hour, and took the etiological examination before giving antibiotics.

Second, $30 \mathrm{ml} / \mathrm{kg}$ of crystalloid fluids was used for rapid volume resuscitation within three hours, and the initial target of mean arterial pressure (MAP) was $65 \mathrm{mmHg}$. If the MAP was not achieved the target within one hour, noradrenaline was used for increasing the blood pressure. Third, we looked for and controlled the source of infection actively. For patients with a definite source of infection, we controlled the source of infection by minimally invasive drainage, surgical debridement, removal of a central venous catheter and sputum aspiration by bronchoscope, etc. To emphasize; we follow the guidelines for other treatment strategies ${ }^{[5,6]}$.

Data collection and follow-up

The clinical data and laboratory examination of the patients were collected as follows: age, body mass index (BMI), underlying diseases, the length of the first operation, pathogen susceptibility test, antibiotics used, whether shock occurred within 48 hours after entering ICU, the number of blood leukocytes, lymphocyte percentage, neutrophil percentage, international standardized ratio (INR), activated partial thromboplastin time (APTT), albumin, creatinine, cardiac troponin I (TNI), procalcitonin (PCT), lactic acid (Lac), base excess (BE), oxygenation index (PaO2 / FiO2) after entering ICU, sequential organ failure (SOFA) score and acute physiological function and chronic health evaluation ( APACHE) II score within $24 \mathrm{~h}$ after entering ICU. Unless otherwise stated, the first test after entering ICU was used for analysis. They were followed up to 90 days in the clinic or by phone call. 
The data of continuous variables were statistically described by mean \pm standard deviation. The noncontinuous variables were described by median (Quartile 1 [Q1], Quartile 3 [Q3]). The counting variables were described by numerical value (percentage). The Kaplan-Meier method was used to calculate the survival rate of patients and log-rank test was used for the univariate analysis. Cox regression was used for the multivariate adjusted analyses with forward LR method. Statistical analyses were carried out using SPSS version 24.0 and $P$ values less than 0.05 (two-tailed) were considered significant.

\section{Results}

\section{Patient characteristics}

According to the new definition of sepsis, a total of 181 patients were diagnosed with sepsis and 86 of them were diagnosed with septic shock within 48 hours after entering ICU. There were 13 patients complicated by abdominal bleeding or gastrointestinal bleeding, 16 cases by deep-vein thrombosis, one case by cerebral infarction and one case by myocardial infarction. See Table 1 for baseline characteristics of patients.

The Univariate and multiple survival analyses

The univariate analysis is shown in Table 2. All the sepsis patients were followed up for 90 days; 20 patients died, and the 90 -day all-cause mortality rate was $11.1 \%$. Univariate analysis showed that there were statistically significant differences in BMI, shock within 48h after entering ICU, the number of blood leukocytes, the ratio of lymphocyte to neutrophil, INR, creatinine, PCT, Lac, BE, oxygenation index after entering ICU, SOFA score and APACHE II score within 24h after entering ICU. Among them, BMI more than $20 \mathrm{~kg} / \mathrm{m}^{2}$ was a protective factor; the others were risk factors. Especially, shock within $48 \mathrm{~h}$ after entering ICU, INR, creatinine, Lac, oxygenation index after entering ICU, SOFA score and APACHE II score within 24h after entering ICU had $P$ values less than 0.01 .

See Table 3 for multiple analyses. Those factors with $P$ values less than 0.05 were enrolled in the Cox regression analysis. The results showed that BMI, lactic acid after entering ICU and APACHE II score within $24 \mathrm{~h}$ after entering ICU were independent prognostic factors. The BMI $\otimes 20 \mathrm{~kg} / \mathrm{m}^{2}$ was a protective factor, while lactic acid $₫ 3 \mathrm{mmol} / \mathrm{L}$ after entering the ICU and APACHE II score $₫ 20$ within 24 hours after entering ICU were risk factors. The survival curves of these three factors are shown in figure 1, figure 2 and figure 3 .

\section{Discussion}

Sepsis is one of the most common causes of death in critically ill patients. At present, there are just a few studies focused on postoperative sepsis. This study focuses on sepsis after operation of gastrointestinal tumor. In this study, the mortality rate is lower than that of sepsis reported in the literature ${ }^{[12]}$, which may 
be related to the fact that most of the infection sources of the patients we selected are abdominal infection, and we can actively control the infection sources by multidisciplinary cooperation. In this study, 181 patients with sepsis who were admitted to ICU after operation of gastrointestinal tumor were analyzed retrospectively and we found that $\mathrm{BMI} \otimes 20 \mathrm{~kg} / \mathrm{m}^{2}$, lactic acid $\triangle 3 \mathrm{mmol} / \mathrm{L}$ after entering the ICU and APACHE II score 20 within $24 \mathrm{~h}$ after entering ICU were independent pro gnostic factors.

The World Health Organization classified BMI as follows: BMI $₫ 18.5 \mathrm{~kg} / \mathrm{m}^{2}$ was underweight, $18.5 \leq \mathrm{BMI} 25$ $\mathrm{kg} / \mathrm{m}^{2}$ was normal weight, $25 \leq \mathrm{BMI} \otimes 30 \mathrm{~kg} / \mathrm{m}^{2}$ was overweight and $\mathrm{BMI} \geq 30 \mathrm{~kg} / \mathrm{m}^{2}$ was obesity ${ }^{[13]}$. In this study, we found that patients with BMI $20 \mathrm{~kg} / \mathrm{m}^{2}$ had a better prognosis than those with $B M I \leq 20 \mathrm{~kg} / \mathrm{m}^{2}$, so we guessed that BMI $20 \mathrm{~kg} / \mathrm{m}^{2}$ might be a protective factor. However, the number of patients in this study was limited, and we did not conduct a more detailed stratified study. There were numerous reports about the relationship between $\mathrm{BMI}$ and the prognosis of sepsis, though the results were still controversial ${ }^{[14,15]}$. Matthaios PO et al. ${ }^{[16]}$ found that the mortality of obese patients with sepsis increased significantly. But one recent meta-analysis divided sepsis patients into three groups: Overweight (25】

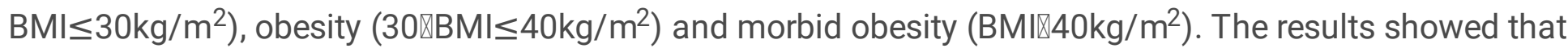
the death risk of overweight patients with sepsis was reduced, while obesity and morbid obesity patients with sepsis did not increase the death risk. The reason for this controversy might be related to the distribution of adipose tissue. It was reported that the visceral fat (VAT) accumulation detected by CT scan was a risk factor for poor prognosis of sepsis. Sepsis patients with a high ratio of VAT area to the subcutaneous fat (SAT) area had an increased risk of death and organ damage ${ }^{[17]}$. In future, more detailed and rigorous studies should be designed to clarify the relationship between sepsis and BMI.

Lactic acid was constantly produced in metabolism and exercise, but its concentration generally did not rise. Only when the production of lactic acid was accelerated and lactate could not be deleted in time, its concentration would increase. Generally speaking, when the energy of the tissue could not be satisfied by aerobic respiration, the tissue could not get enough oxygen or could not deal with oxygen fast enough, the concentration of lactic acid would rise. Hence, sepsis and septic shock guidelines used lactic acid as an indicator of tissue hypoperfusion and as a target for fluid resuscitation ${ }^{[5,6]}$. Many studies had shown that lactate was an independent risk factor for sepsis prognosis ${ }^{[18-20]}$. In our study, it was also confirmed that the lactic acid $\mathbb{3} \mathrm{mmol} / \mathrm{L}$ after entering the ICU was an independent risk factor for sepsis patients after the gastrointestinal tumor surgery.

There were numerous scoring systems for evaluating the severity of critical patients, such as SOFA score and APACHE II score ${ }^{[21-23]}$. APACHE II score was considered as the gold standard for risk assessment of critical patients in the past. Several studies confirmed that APACHE II score is an independent risk factor for the prognosis of sepsis patients ${ }^{[24,25]}$. In our study, we found that the SOFA score and APACHE II score within 24 hours after entering ICU were statistically significant in the univariate analysis, while the multivariate analysis showed that only APACHE II score $\mathbb{2 0}$ was an independent risk factor in this group. However, there was evidence that APACHE II score might provide inaccurate information in some patients, 
for example, in patients with unconsciousness, the score might be too high ${ }^{[26]}$. Therefore, we need to increase the sample size to confirm this result in the future.

The limitations of this study should be referred. First, this study was a retrospective study and the subjects of this study were patients with sepsis who were admitted to ICU after operation of gastrointestinal tumor, so, whether the results could be extended to all sepsis populations remains to be confirmed. Second, patients with sepsis in the general ward were not included in this study, and most of these patients improved in our hospital. Therefore, the mortality of patients with sepsis after gastrointestinal surgery might be overestimated in our study. In the future, we will design prospective research to verify it. Third, there were several missing data, especially BNP, echocardiography, etc. So we could not accurately evaluate their impact on the prognosis of sepsis patients. Finally, the small sample size of this study increased the risk of type two error which made the study power limited. We just hope there will be more large-scale researches to confirm these results in the future.

\section{Conclusion}

The 90 -day all-cause mortality rate was $11.1 \%$ in our study. BMI $20 \mathrm{~kg} / \mathrm{m}^{2}$ was a protective factor, while lactic acid $₫ 3 \mathrm{mmol} / \mathrm{L}$ after entering the ICU and APACHE II score $₫ 20$ within 24 hours after entering ICU were independent risk factors on the prognosis of sepsis after the gastrointestinal tumor surgery in ICU.

\section{Abbreviations}

BMI: body mass index; INR: International standardized ratio; APTT: activated partial thromboplastin time;

TNI: cardiac troponin I; PCT: procalcitonin ; Lac; lactic acid; BE: base excess; SOFA score: sequential organ failure and acute score; APACHE II score: Acute Physiology and Chronic Health Evaluation II score.

\section{Declarations}

\section{Acknowledgements}

None.

\section{Funding}

The study was funded by B.Braun Anaesthesia Science Research Foundation (BBFD-2015-16).

\section{Availability of data and materials}

Data will be shared after this study is published.

\section{Ethics approval and consent to participate}


We received the approval of the Medical Ethical Committee of Peking University Cancer Hospital. All patients or their near kin in our study provided informed consent.

\section{Consent for publication}

Not applicable.

\section{Conflict of interest}

None.

\section{References}

1. Fleischmann C, Scherag A, Adhikari NK, Hartog CS, Reinhart K. Assessment of Global Incidence and Mortality of Hospital-treated Sepsis. Current Estimates and Limitations[J]. Am J Respir Crit Care Med. 2016;193(3):259-72.

2. Singer M, Deutschman CS, Seymour CW, Shankar-Hari M, Annane D, Bauer M, et al. The Third International Consensus Definitions for Sepsis and Septic Shock (Sepsis-3) [J]. The Journal of the American Medical Association. 2016;315(8):775-87.

3. Sawyer RG, Claridge JA, Nathens AB, Rotstein OD, Duane TM, Evans HL, et al. Trial of Short-Course Antimicrobial Therapy for Intraabdominal Infection [J]. N Engl J Med. 2015;372(21):1996-2005.

4. Sartelli M, Catena F, Abu-Zidan FM, Ansaloni L, Biff WL, Boermeester MA, et al. Management of intraabdominal infections: Recommendations by the WSES 2016 consensus conference [J]. World Journal of Emergency Surgery. 2017; 12:22.

5. Rhodes A, Evans LE, Alhazzani W, Levy MM, Antonelli M, Ferrer R, et al. Surviving Sepsis Campaign: International Guidelines for Management of Sepsis and Septic Shock [J]. Crit Care Med. 2017;45(3):486-552.

6. The Surviving Sepsis Campaign Bundle: 2018 update [J] Levy MM, Evans LE, Rhodes A.. The Surviving Sepsis Campaign Bundle: 2018 update [J]. Intensive Care Med. 2018; 44(6):925-8.

7. Fraunberger P, Wang Y, Holler E, Parhofer KG, Nagel D, Walli AK, et al. Prognostic value of interleukin 6 , procalcitonin, and c-reactive protein levels in intensive care unit patients during first increase of fever [J]. Shock. 2006;26(1):10-2.

8. Yanaral TU, Idin IK, Uzman S, Toptas M, Bican G. The prognostic value of procalcitonin and C-reactive protein in critically ill patients A comparison with APACHE II and SOFA scores: 12AP5-2. Eur J Anaesth. 2010;1068:27.

9. Annals of Cardiac Anaesthesia. | Apr-Jun-2016 | Vol 19 | Issue 2.

10. REFERENCES.

11. Tanriverdi H, Tor MügeMeltem, Kart L, Altin R, Atalay F, SumbSümbüloğlu V. Prognostic value of serum procalcitonin and C-reactive protein levels in critically ill patients who developed ventilator- 
associated pneumonia [J]. Annals of Thoracic Medicine. 2015;10(2):137-42.

12. Ríos-Toro J-J, Márquez-Coello Mercedes, García-álvarez José-María, Andrés Martín-Aspas, Ricardo Rivera-Fernández, Ana Sáez de Benito, et al. Soluble membrane receptors, interleukin 6, procalcitonin and $C$ reactive protein as prognostic markers in patients with severe sepsis and septic shock [J]. PLOS ONE. 2017; 12(4):e0175254.

13. Ryoo SM, Lee JB, Lee YS, Lee JH, Lim KS, Huh JW, et al. Lactate Level Versus Lactate Clearance for Predicting Mortality in Patients With Septic Shock Defined by Sepsis-3 [J]. Crit Care Med. 2018;46(6):e489-95.

14. Herrán-Monge R, Muriel-Bombín A, García-García MM, Merino-García PA, Martínez-Barrios M, Andaluz $D$, et al. Epidemiology and Changes in Mortality of Sepsis After the Implementation of Surviving Sepsis Campaign Guidelines [J]. Journal of Intensive Care Medicine. 2019;34(9):740-50.

15. Organization WH. Obesity: preventing and managing the global epidemic: report of a WHO consultation on obesity[J]. Geneva World Health Organization. 2000;894(1):18-30.

16. Trivedi V, Bavishi C, Jean R. Impact of obesity on sepsis mortality: A systematic review [J]. J Crit Care. 2015;30(3):518-24.

17. Wang S, Liu X, Chen Q, Liu C, Huang C, Fang X. The role of increased body mass index in outcomes of sepsis: a systematic review and meta-analysis [J]. BMC Anesthesiol. 2017;17(1):118.

18. Papadimitriou-Olivgeris M, Aretha D, Zotou A, Koutsileou K, Zbouki A, Lefkaditi A, et al. The Role of Obesity in Sepsis Outcome among Critically III Patients: A Retrospective Cohort Analysis [J]. BioMed Research International. 2016:5941279.

19. Pisitsak C, Lee JG, Boyd JH, Coxson HO, Russell JA, Walley KR. Increased Ratio of Visceral to Subcutaneous Adipose Tissue in Septic Patients Is Associated With Adverse Outcome [J]. Critical Care Medicine. 2016;44(11):1966-73.

20. Malmir J, Bolvardi E, Afzal Aghaee M. Serum lactate is a useful predictor of death in severe sepsis and septic shock [J]. Reviews in Clinical Medicine. 2014;1(3):97-104.

21. Lokhandwala S, Andersen LW, Nair S, Patel P, Cocchi MN, Donnino MW. Absolute lactate value versus relative reduction as a predictor of mortality in severe sepsis and septic shock [J]. Journal of critical care. 2016;37:179-84.

22. Siddiqui I, Jafri L, Abbas Q, Raheem A, Haque AU. Relationship of serum procalcitonin, c-reactive protein, and lactic acid to organ failure and outcome in critically ill pediatric population [J]. Indian Journal of Critical Care Medicine. 2018;22(2):91-5.

23. Ho KM. Combining Sequential Organ Failure Assessment (SOFA) Score with Acute Physiology and Chronic Health Evaluation (APACHE) II Score to Predict Hospital Mortality of Critically III Patients [J]. Anaesthesia intensive care. 2007;35(4):515-21.

24. Raith EP, Udy AA, Bailey M, McGloughlin S, Maclsaac C, Bellomo R, et al. Prognostic Accuracy of the SOFA Score, SIRS Criteria, and qSOFA Score for In-Hospital Mortality Among Adults With Suspected Infection Admitted to the Intensive Care Unit [J]. JAMA. 2017;317(3):290-300. 
25. Probst L, Schalk E, Liebregts T, Zeremski V, Tzalavras A, Bergwelt-Baildon MV, et al. Prognostic accuracy of SOFA, qSOFA and SIRS criteria in hematological cancer patients: a retrospective multicenter study [J]. Journal of Intensive Care. 2019;7:41.

26. Liu X, Shen Y, Li Z, Fei A, Wang H, Ge Q, et al. Prognostic significance of APACHE II score and plasma suPAR in Chinese patients with sepsis: a prospective observational study [J]. BMC Anesthesiol. 2015;16(1):46.

27. Giamarellos-Bourboulis EJ, Norrby-Teglund A, Mylona V, Savva A, Tsangaris I, Dimopoulou I, et al. Risk assessment in sepsis: a new prognostication rule by APACHE II score and serum soluble urokinase plasminogen activator receptor [J]. Crit Care. 2012;16(4):R149.

28. Vincent JL, Opal SM, Marshall JC. Ten reasons why we should NOT use severity scores as entry criteria for clinical trials or in our treatment decisions [J]. Critical care medicine. 2010;38(1):28.

\section{Tables}

Table1 Baseline characteristics of sepsis patients 


\begin{tabular}{|c|c|}
\hline Baseline characteristics & Number (\%) \\
\hline Age, median (Q1, Q3) & $65(59,71)$ \\
\hline \multicolumn{2}{|l|}{ Sex } \\
\hline Male & $145(80.1)$ \\
\hline Female & $36(19.9)$ \\
\hline BMI, Mean (SD), kg/m2 & $23.5(0.3)$ \\
\hline \multicolumn{2}{|l|}{ Tumor type } \\
\hline Gastric cancer & $91(50.3)$ \\
\hline Colorectal cancer & $84(46.4)$ \\
\hline Other abdominal tumors & $6(3.3)$ \\
\hline \multicolumn{2}{|l|}{ Coexisting conditions ${ }^{a}$} \\
\hline Hypertension & $64(35.4)$ \\
\hline Diabetes & $32(17.7)$ \\
\hline Coronary heart disease & $17(9.4)$ \\
\hline Chronic obstructive pulmonary disease & $11(6.1)$ \\
\hline Arrhythmia & $9(5.0)$ \\
\hline Chronic renal insufficiency & $2(1.1)$ \\
\hline \multicolumn{2}{|l|}{ Location of infection ${ }^{b}$} \\
\hline Abdominal infection & $134(74.0)$ \\
\hline Enterogenous infection & $12(6.6)$ \\
\hline Intrathoracic infection & $17(9.4)$ \\
\hline Pulmonary infection & $31(17.1)$ \\
\hline Skin and soft tissue infection & $6(3.3)$ \\
\hline Surgical wound infection & $4(2.2)$ \\
\hline Central line-associated bloodstream infection & $3(1.7)$ \\
\hline Urinary tract infection & $2(1.1)$ \\
\hline Length of first operation, median(Q1,Q3), min & $195(140,246)$ \\
\hline
\end{tabular}

a 27 patients had two or more chronic diseases. 
b 31 patients were infected with two or more locations.

Table2 The univariate analysis of sepsis patients 


\begin{tabular}{|c|c|c|c|}
\hline Items & Number (\%) & Survival rate at 90-day & $P$ value \\
\hline Age, years & & & 0.840 \\
\hline$\leqq 65$ & $96(53.0)$ & 0.885 & \\
\hline$\triangle 65$ & $85(47.0)$ & 0.894 & \\
\hline Sex & & & 0.254 \\
\hline Male & $145(80.1)$ & 0.876 & \\
\hline Female & $36(19.9)$ & 0.944 & \\
\hline $\mathrm{BMI}, \mathrm{kg} / \mathrm{m}^{2}$ & & & 0.018 \\
\hline$\leqq 20$ & $37(20.4)$ & 0.784 & \\
\hline$\bowtie 20$ & $144(79.6)$ & 0.917 & \\
\hline Charlson score & & & 0.356 \\
\hline$\leqq 3$ & $142(78.5)$ & 0.901 & \\
\hline$\varangle 3$ & $39(21.5)$ & 0.846 & \\
\hline Length of first operation, min & & & 0.361 \\
\hline$\leqq 240$ & $129(71.3)$ & 0.876 & \\
\hline$\llbracket 240$ & $52(28.7)$ & 0.923 & \\
\hline Empirical anti infection evaluation & & & 0.729 \\
\hline Sensitive & $132(72.9)$ & 0.894 & \\
\hline Resistance & $18(10.0)$ & 0.833 & \\
\hline No pathogen detected & $31(17.1)$ & 0.903 & \\
\hline Shock within $48 \mathrm{~h}$ after entering ICU & & & 0.001 \\
\hline No & $95(52.5)$ & 0.979 & \\
\hline Yes & $86(47.5)$ & 0.791 & \\
\hline Number of blood leukocytes, $10^{9} / \mathrm{L}$ & & & 0.010 \\
\hline$\leqq 4$ & $31(17.1)$ & 0.774 & \\
\hline $4 \llbracket W B C \leq 12$ & $77(42.6)$ & 0.963 & \\
\hline$\nabla 12$ & $73(40.3)$ & 0.863 & \\
\hline Ratio of lymphocyte to neutrophil & & & 0.035 \\
\hline$\leqq 0.15$ & $148(81.8)$ & 0.912 & \\
\hline
\end{tabular}


$\bowtie 0.15$

$33(18.2) \quad 0.788$

International standardized ratio

$\leqq 1.5$

$127(70.2) \quad 0.937$

$\nabla 1.5$

$54(29.8)$

0.778

Activated partial thromboplastin time, $S$

0.064

$\leqq 50$

$138(76.2) \quad 0.913$

\50

$43(23.8) \quad 0.814$

Albumin, g/L

0.058

$\leqq 30$

$99(54.7) \quad 0.848$

邓30

$82(45.3) \quad 0.939$

Creatinine, umol/L

0.001

$\leqq 120$

$150(82.9) \quad 0.927$

$\nabla 120$

31 (17.1) $\quad 0.710$

Cardiac troponin I, ng/ml

$\leqq 0.05$

$\bowtie 0.05$

Procalcitonin, $\mathrm{ng} / \mathrm{ml}$

$\begin{array}{lll}\leqq 5 & 93(51.4) & 0.946 \\ \triangle 5 & 88(48.6) & 0.830\end{array}$

Lactic acid, mmol/L

$\begin{array}{lll}\leqq 3 & 128(70.7) & 0.938 \\ ₫ 3 & 53(29.3) & 0.774\end{array}$

Base excess, mmol/L

$\leqq-3$

ه-3

Oxygenation index, $\mathrm{mmHg}$

$\leqq 200$

$₫ 200$

SOFA score
138 (76.2) $\quad 0.913$

$43(23.8) \quad 0.814$

0.011

0.063

$\begin{array}{ll}101(55.8) & 0.941 \\ 80(44.2) & 0.825\end{array}$

\begin{tabular}{ll} 
& \\
\hline $97(53.6)$ & 0.825 \\
$84(46.4)$ & 0.964
\end{tabular}

0.003

0.001 


\begin{tabular}{|c|c|c|c|}
\hline$\leqq 8$ & $124(68.5)$ & 0.968 & \\
\hline$\bigotimes 8$ & 57 (31.5) & 0.719 & \\
\hline APACHE II score & & & 0.001 \\
\hline$\leqq 20$ & $124(68.5)$ & 0.976 & \\
\hline$\triangle 20$ & 57 (31.5) & 0.702 & \\
\hline
\end{tabular}

Table3 Multiple analysis of sepsis patients

\begin{tabular}{|lllll|}
\hline Factors & RR & \multicolumn{2}{c|}{$95 \%$ interval } & Pvalue \\
\cline { 3 - 4 } & & Lower limit & Upper limit & \\
\hline BMI & 0.199 & 0.076 & 0.522 & 0.001 \\
\hline Lactic acid & 3.333 & 1.290 & 8.610 & 0.013 \\
\hline APACHE II score & 14.479 & 4.145 & 50.580 & 0.001 \\
\hline
\end{tabular}

Figures

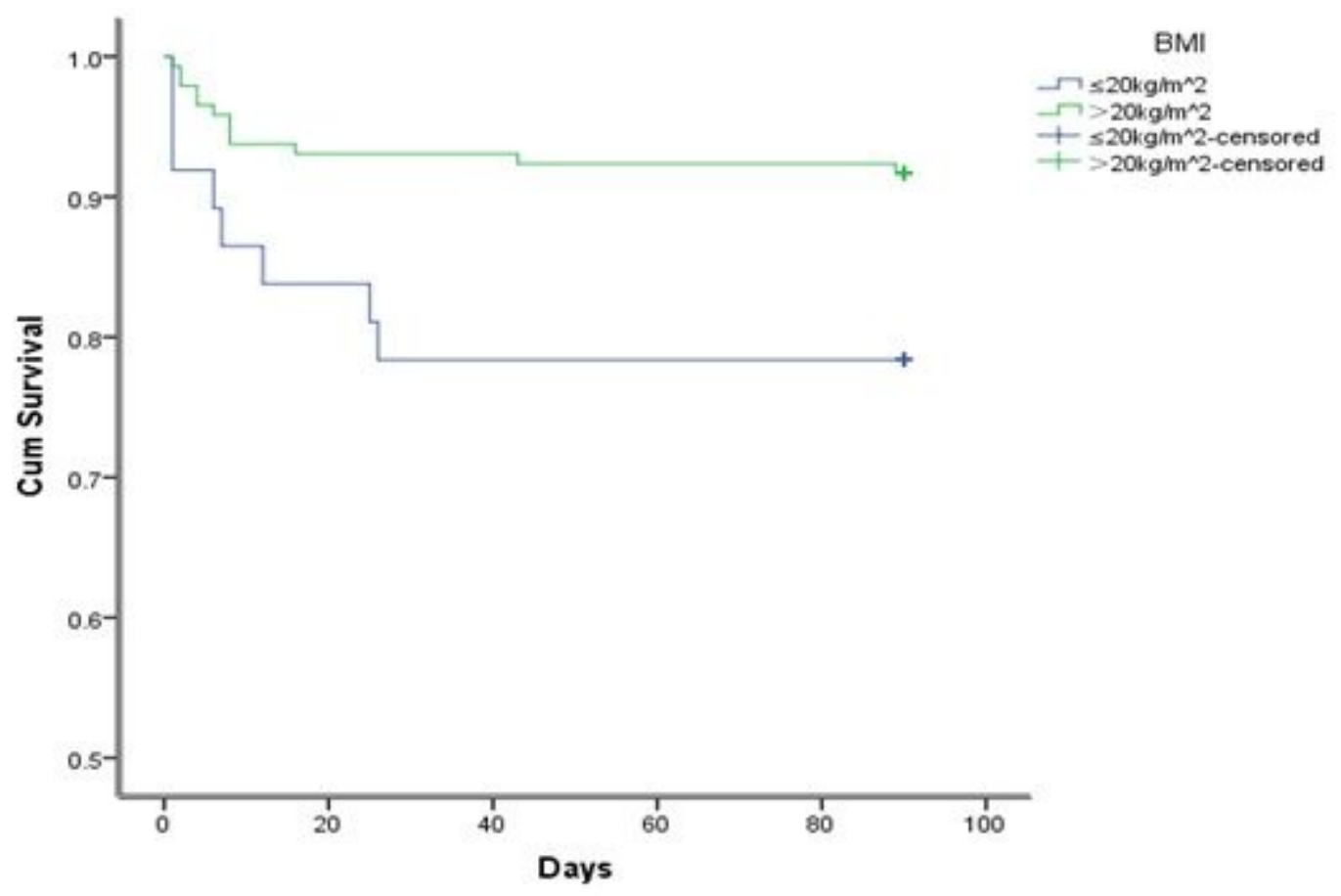


Figure 1

Kaplan-Meier survival curves of BMI on overall survival at 90 days

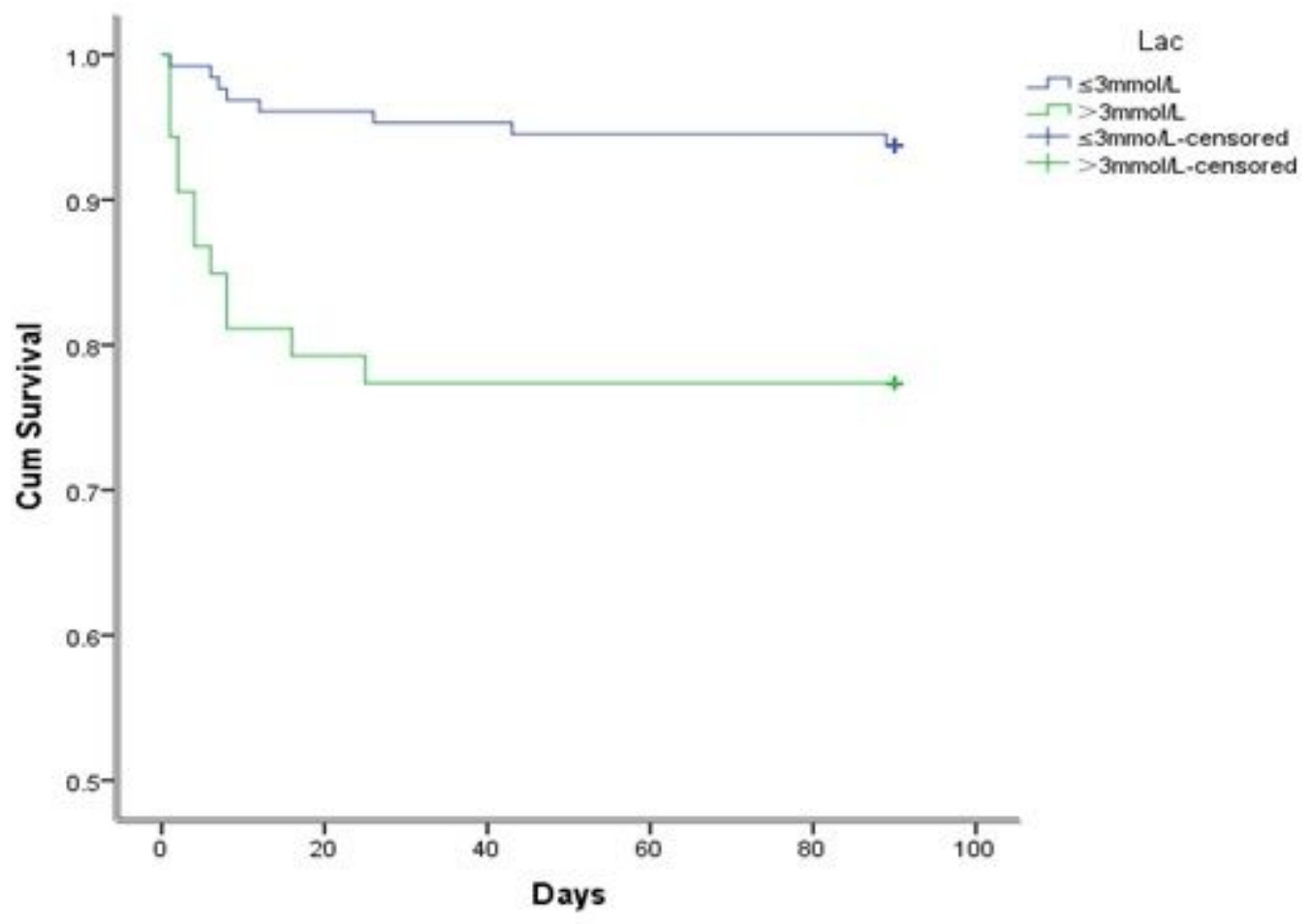

Figure 2

Kaplan-Meier survival curves of Lac on overall survival at 90 days

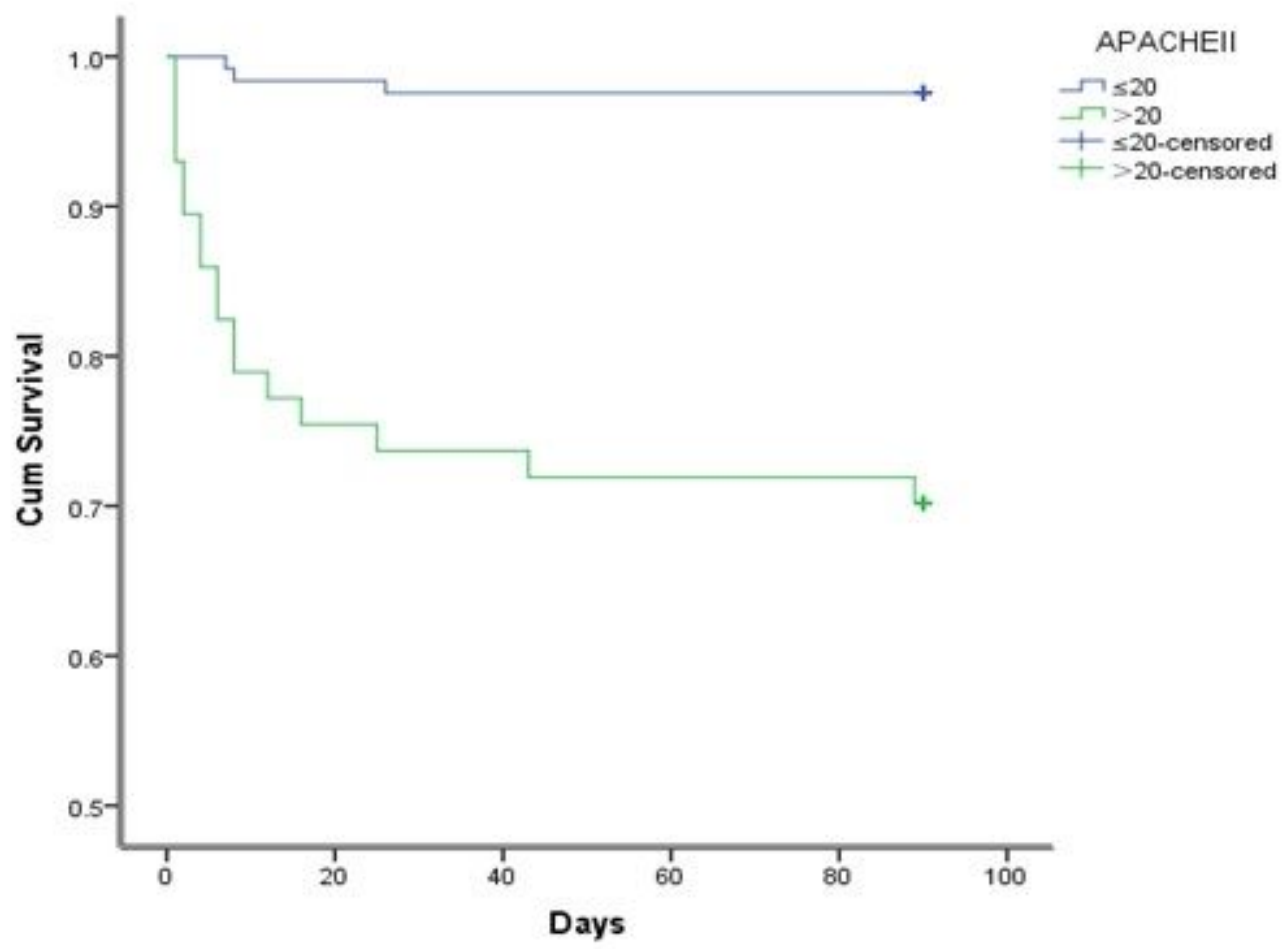


Figure 3

Kaplan-Meier survival curves of APACHE II score on overall survival at 90 days 